\title{
(2) OPEN ACCESS \\ Seizure frequency, healthcare resource utilisation and mortality in childhood epilepsy: a retrospective cohort study using the THIN database
}

\author{
Melissa Myland 0 , ${ }^{1}$ Brian Buysse, ${ }^{1}$ Wan Tsong, ${ }^{2}$ G Sarah Power, ${ }^{1}$ Douglas Nordli, ${ }^{3}$ \\ Richard F M Chin ${ }^{4,5}$
}

\begin{abstract}
- Additional material is published online only. To view please visit the journal online (http://dx.doi.org/10.1136/ archdischild-2019-316910).

IIQVIA, London, UK

'Eisai Inc, Woodcliff Lake, UK ${ }^{3}$ Children's Hospital of Los Angeles, Los Angeles, USA ${ }^{4}$ Muir Maxwell Epilepsy Centre, Edinburgh, UK

${ }^{5}$ Paediatric Neurosciences,

Royal Hospital for Sick Children, Edinburgh, UK
\end{abstract}

Correspondence to Dr Richard F M Chin, Muir Maxwell Epilepsy Centre, Edinburgh EH8 9XD, UK; r.chin@ed.ac.uk

Received 24 January 2019 Revised 7 May 2019 Accepted 8 May 2019 Published Online First 4 July 2019
Check for updates

(C) Author(s) (or their employer(s)) 2019. Re-use permitted under CC BY-NC. No commercial re-use. See rights and permissions. Published by BMJ.

To cite: Myland M, Buysse B Tsong W, et al. Arch Dis Child 2019;104:1070-1076.

\begin{abstract}
Objective To understand the association of seizure frequency with healthcare resource utilisation (HCRU) and mortality in UK children with epilepsy (CWE).

Design Retrospective cohort study.

Setting Routinely collected data in primary care from The Health Improvement Network UK database.

Patients CWE $\geq 1$ and $<18$ years of age with a record of seizure frequency were included in mortality analyses from 2005 to 2015 and HCRU analyses from 2010 to 2015.

Main outcome measures Frequency of HCRU

What is already known?

- Epilepsy is a serious neurological disorder which is prevalent in the paediatric population.

- Treatment with anti-epileptic drugs aims to reduce seizure frequency but not all patients may respond to initial treatment.

- The relationship between seizure frequency, healthcare resource utilisation and mortality has not been well-studied in children with epilepsy (CWE).
\end{abstract} contacts during the year following latest seizure frequency and mortality (descriptive and Cox proportional hazards regression) from first record of seizure frequency.

Results Higher seizure frequency was related to increased HCRU utilisation and mortality. In negative binomial regression, each category increase in seizure frequency related to $11 \%$ more visits to general practitioners, 35\% more inpatient admissions, 15\% more outpatient visits and increased direct HCRU costs (24\%). 11 patients died during 12490 patient-years follow-up. The unadjusted HR of mortality per higher category of seizure frequency was 2.56 (95\% Cl: 1.52 to 4.31 ). Adjustment for age and number of prescribed antiepileptic drugs at index attenuated this estimate to 2.11 (95\% Cl: 1.24 to 3.60).

Conclusion Higher seizure frequency is associated with greater HCRU and mortality in CWE in the UK. Improvement in seizure control may potentially lead to better patient outcomes and reduced healthcare use.

\section{BACKGROUND}

Epilepsy is one of the most common serious neurological disorders and is prevalent in $0.5 \%$ of UK children. ${ }^{12}$ Up to $70 \%$ of people with epilepsy will become seizure-free ${ }^{3}$ by using anti-epileptic drugs (AEDs). ${ }^{4}$ AED regimens are individualised according to seizure type, epilepsy syndrome, concurrent medications, comorbidities and patient preferences. ${ }^{5}$

Non-adherence to AEDs often results in increased seizure frequency, hospital admissions, status epilepticus and premature death. ${ }^{6}$ Improved seizure control through optimisation of the use of AEDs may influence healthcare resource utilisation (HCRU) (including general practitioner (GP) visits, secondary care referrals and hospitalisations) and mortality. An American hospital-based study suggested that increased seizure frequency is associated with greater HCRU. ${ }^{7}$ Since then, there have been changes in the recommended

\section{What this study adds?}

- Substantial decreases in primary and secondary care resource utilisation are associated with decreases in seizure frequency in CWE.

- Greater seizure frequency is associated with an increased mortality in CWE.

management of epilepsy and availability of newer AEDs in the UK. ${ }^{5}$ However, little is known about the relationship between seizure frequency, mortality and HCRU in the paediatric epilepsy population.

This study used routine primary care from UK electronic medical records (EMRs) captured within The Health Improvement Network (THIN) Database. The aim of the study was to investigate the association between seizure frequency, HCRU and mortality in children with epilepsy (CWE). ${ }^{8}$ Specifically, our objectives were as follows: (1) to characterise CWE in terms of seizure frequency and HCRU, (2) to quantify the relationship between seizure frequency and HCRU and (3) to assess the relationship between seizure frequency and all-cause mortality.

\section{METHODS}

This retrospective cohort study aimed to describe HCRU and mortality according to seizure frequency in CWE using anonymised EMR data from the THIN database. THIN is a large primary care database ${ }^{9} 10$ which captures EMR data on prescriptions, diagnoses and symptoms in patients seen in GP practices. THIN has data from over 15 million patients, of which over 2.9 million are currently active, representing nearly $6 \%$ of the UK population. UK-based GPs provide care for free at the point of delivery, electronically prescribe 
medications, provide referrals to secondary care and provide joint care of chronic patients seen in secondary care. ${ }^{11}$

For the HCRU analysis, the study time period was from 01 January 2010 to 31 December 2015 with the index date being the most recent record of seizure frequency. The study time period was from 1 January 2005 to 31 December 2015 for mortality analysis with the index date being the first record of seizure frequency. The time period for the mortality analysis was longer to capture more deaths, a rarer outcome in the paediatric population. Additionally, the most relevant and recent HCRU costs were of interest to understand the impact of newer AEDs and national guidelines for epilepsy management. ${ }^{5}$

Patients were included in the study if they were $\geq 1$ and $<18$ years old at index date with $\geq 1$ record of seizure frequency, with a diagnosis of epilepsy at any point before or after index date. Epilepsy was identified based on Read diagnosis codes used in a previous validation study ${ }^{8}$ and were reviewed by a clinician (RC)(online supplementary appendix). Another previous Wales-based study indicated that epilepsy diagnosis codes had a sensitivity of $86 \%$ and specificity of $97 \% .{ }^{12}$ Seizure frequency was characterised by the presence of Additional Health Data or Read codes, whichever was present. Codes were aligned to categories of at least daily, weekly, monthly, quarterly, yearly and less frequent according to text descriptions.

\section{Statistical analysis}

Clinical and sociodemographic details were assessed at baseline. ${ }^{13}$ HCRU included GP encounters (telephone calls, face-toface visits, nurse visits), outpatient visits (day visits to a specialist), inpatient hospital admissions, accident and emergency (A\&E) visits resulting in inpatient admissions to hospital (A\&E admissions) and number of AEDs. As THIN contains no information on unit costs, averaged National Health Service tariffs were used to estimate HCRU costs in models. ${ }^{14} 15$
The association between seizure frequency and HCRU was evaluated in the year following index date using a negative binomial regression model using incidence rate ratios. To retain patients with <1 year HCRU data, HCRU was standardised to 'number of health service encounters per year' and reported as means (SD).

Cox proportional hazards regression was used to analyse the association between seizure frequency and all-cause mortality with the proportional hazards assumption satisfied via assessment using Schoenfeld and cumulative residuals. The dependent variable was the interval between earliest record of seizure frequency (from 2005) to date of death. When death was not recorded, patients were censored at the earliest transfer out of practice, age 18 years or 31 December 2015 .

The 'change in estimate' approach ${ }^{16}$ was used to determine whether factors altered the crude regression coefficient of seizure frequency (coded 1-5) by more than $10 \%$; if this criterion was satisfied, the covariate was added into the final multiple adjusted regression model. Covariates for assessment included: age at index, gender, calendar year at index, Townsend score as marker of socioeconomic status (quintiles), epilepsy diagnosis prior to versus following index date, number of AEDs prescribed at index and comorbidities recorded ever. ${ }^{17}$ In all, 22 variables were assessed for effect modification. A Bonferroni correction was applied to the significance level, changing it from 0.05 to 0.0023 .

SAS V.9.4 (Cary, NC, USA) was used to conduct the analysis.

\section{RESULTS}

\section{Baseline characteristics}

After applying inclusion and exclusion criteria, 1273 patients were included for assessment of the association of seizure frequency and HCRU and 3324 for seizure frequency and

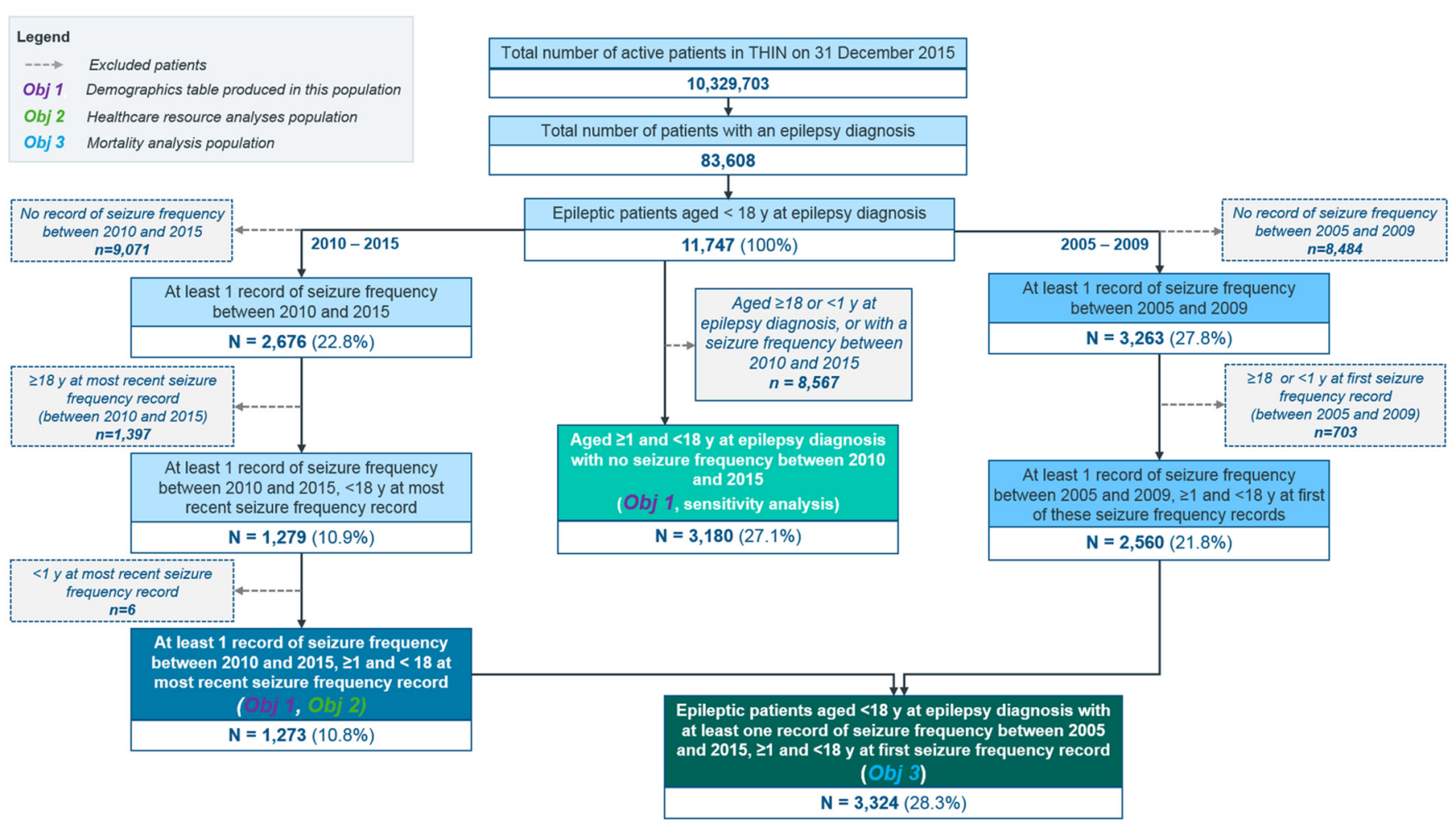

Figure 1 Overview of population attrition. 


\section{Original article}

Table 1 Baseline characteristics of the population included in analyses

\begin{tabular}{|c|c|c|c|}
\hline Characteristic & $\begin{array}{l}\text { Patients with } \geq 1 \text { record of seizure } \\
\text { frequency after } 1 \text { st January } 2010 \\
\text { (HCRU population) }\end{array}$ & $\begin{array}{l}\text { Patients with } \geq 1 \text { record of seizure } \\
\text { frequency after } 1 \text { st January } 2005 \\
\text { (mortality population) }\end{array}$ & $\begin{array}{l}\text { Patients with no record of seizure } \\
\text { frequency after 1st January } \\
2010 \text { (sensitivity analysis population) }\end{array}$ \\
\hline Number of patients & 1273 & 3324 & 3180 \\
\hline \multicolumn{4}{|l|}{ Gender, $n(\%)$} \\
\hline Female & $621(49.1)$ & $1565(47.1)$ & $1442(45.3)$ \\
\hline Male & $645(50.9)$ & $1759(52.9)$ & $1738(54.7)$ \\
\hline Missing & $0(0.0)$ & $0(0.0)$ & $0(0.0)$ \\
\hline \multicolumn{4}{|l|}{ Age at index* (years) } \\
\hline Median (Q1, Q3 †) & $14.6(10.1,17.4)$ & $12.7(8.5,16.1)$ & $9.2(5.1,13.6)$ \\
\hline \multicolumn{4}{|l|}{ Age category at index ${ }^{*} \mathrm{n}(\%)$} \\
\hline $1-3$ & $47(3.7)$ & $228(6.9)$ & $553(17.4)$ \\
\hline $4-11$ & $400(31.4)$ & $1246(37.5)$ & $1579(49.7)$ \\
\hline $12-17$ & $826(64.9)$ & $1850(55.7)$ & $1048(33.0)$ \\
\hline \multicolumn{4}{|l|}{ Townsend score, quintiles, n (\%) } \\
\hline First quintile (least deprived) & $180(14.1)$ & $383(11.5)$ & $497(15.6)$ \\
\hline Second quintile & $183(14.4)$ & $365(11.0)$ & $463(14.6)$ \\
\hline Third quintile & $205(16.1)$ & $407(12.2)$ & $532(16.7)$ \\
\hline Fourth quintile & $243(19.1)$ & $476(14.3)$ & $606(19.1)$ \\
\hline Fifth quintile (most deprived) & $217(17.0)$ & $441(13.3)$ & $540(17.0)$ \\
\hline Missing $\ddagger$ & $245(19.2)$ & $1252(37.7)$ & $542(17.0)$ \\
\hline \multicolumn{4}{|c|}{ Timing of epilepsy diagnosis relative to most index record of seizure frequency, $n(\%)$} \\
\hline Epilepsy diagnosis prior & $1227(96.4)$ & 3079 (92.6) & N/A \\
\hline Epilepsy diagnosis post & $46(3.6)$ & $245(7.4)$ & N/A \\
\hline Missing & $0(0.0)$ & $0(0.0)$ & $\mathrm{N} / \mathrm{A}$ \\
\hline \multicolumn{4}{|l|}{ Seizure frequency at index, $\mathrm{n}(\%)$} \\
\hline At least daily & $130(10.2)$ & $354(10.6)$ & $\mathrm{N} / \mathrm{A}$ \\
\hline At least weekly & $146(11.5)$ & $392(11.8)$ & $\mathrm{N} / \mathrm{A}$ \\
\hline At least monthly & $160(12.6)$ & $424(12.8)$ & $\mathrm{N} / \mathrm{A}$ \\
\hline At least once a year & $291(22.9)$ & $862(25.9)$ & $\mathrm{N} / \mathrm{A}$ \\
\hline Less than once a year & $546(42.9)$ & $1292(38.9)$ & $\mathrm{N} / \mathrm{A}$ \\
\hline \multicolumn{4}{|c|}{ Record of AED prescription at index, $\mathrm{n}(\%)$} \\
\hline Yes & $963(75.6)$ & $2582(77.7)$ & $\mathrm{N} / \mathrm{A}$ \\
\hline No & $310(24.4)$ & $742(22.3)$ & $\mathrm{N} / \mathrm{A}$ \\
\hline \multicolumn{4}{|c|}{ AEDs prescribed to at least $5 \%$ of the population at index, $n(\%)$} \\
\hline Sodium valproate & $409(32.1)$ & $1253(37.7)$ & $\mathrm{N} / \mathrm{A}$ \\
\hline Lamotrigine & $233(18.3)$ & $605(18.2)$ & $\mathrm{N} / \mathrm{A}$ \\
\hline Carbamazepine & $195(15.3)$ & $622(18.7)$ & N/A \\
\hline Levetiracetam & $167(13.1)$ & $220(6.6)$ & $\mathrm{N} / \mathrm{A}$ \\
\hline Topiramate & $71(5.6)$ & $173(5.2)$ & N/A \\
\hline \multicolumn{4}{|c|}{ Total number of AEDs prescribed at index, $\mathrm{n}(\%)$} \\
\hline None & $310(24.4)$ & $742(22.3)$ & $\mathrm{N} / \mathrm{A}$ \\
\hline $1-2$ & $885(69.5)$ & $2431(73.1)$ & $\mathrm{N} / \mathrm{A}$ \\
\hline $3-4$ & $\S$ & $\S$ & $\mathrm{N} / \mathrm{A}$ \\
\hline $5-6$ & $\S$ & $\S$ & $\mathrm{N} / \mathrm{A}$ \\
\hline \multicolumn{4}{|c|}{ Selected recorded comorbidities (ever), most frequent (n, \%)ף } \\
\hline Any of the below comorbidities & $495(38.9)$ & $1039(31.3)$ & $722(22.7)$ \\
\hline Asthma & $233(18.3)$ & $532(16.0)$ & $354(11.1)$ \\
\hline Learning disabilities & $115(9.1)$ & $233(7.0)$ & $93(2.9)$ \\
\hline Autism & $75(5.9)$ & $116(3.5)$ & $118(3.7)$ \\
\hline Migraine & $41(3.2)$ & $73(2.2)$ & $46(1.4)$ \\
\hline ADHD & $42(3.3)$ & $67(2.0)$ & $46(1.4)$ \\
\hline Cerebral palsy & $37(2.9)$ & $85(2.6)$ & $67(2.1)$ \\
\hline Diabetes & $21(1.6)$ & $31(0.9)$ & $32(1.0)$ \\
\hline Depression & $20(1.6)$ & $26(0.8)$ & $43(1.4)$ \\
\hline Anxiety disorders & $17(1.3)$ & $30(0.9)$ & $18(0.6)$ \\
\hline Hemiplegia and paraplegia & $14(1.1)$ & $30(0.9)$ & $32(1.0)$ \\
\hline Mental retardation & $13(1.0)$ & $17(0.5)$ & $\S$ \\
\hline
\end{tabular}


Table 1 Continued

\begin{tabular}{|c|c|c|c|}
\hline Characteristic & $\begin{array}{l}\text { Patients with } \geq 1 \text { record of seizure } \\
\text { frequency after } 1 \text { st January } 2010 \\
\text { (HCRU population) }\end{array}$ & $\begin{array}{l}\text { Patients with } \geq 1 \text { record of seizure } \\
\text { frequency after } 1 \text { st January } 2005 \\
\text { (mortality population) }\end{array}$ & $\begin{array}{l}\text { Patients with no record of seizure } \\
\text { frequency after 1st January } \\
2010 \text { (sensitivity analysis population) }\end{array}$ \\
\hline Sleep apnoea & $\S$ & $14(0.4)$ & $15(0.5)$ \\
\hline Cerebrovascular disease (including stroke) & $\S$ & $11(0.3)$ & $7(0.2)$ \\
\hline Brain surgery & $\S$ & $9(0.3)$ & $\S$ \\
\hline Chronic lung/pulmonary disease** & $\S$ & $6(0.2)$ & $6(0.2)$ \\
\hline Pain disorders & $6(0.5)$ & $\ddagger \S$ & $7(0.2)$ \\
\hline
\end{tabular}

Note that seven patients in both populations ( $0.5 \% \mathrm{HCRU;} 0.2 \%$ mortality) did not have any records in THIN's Medical File and were considered to have missing data with regards to comorbidities. Seizure frequency is pulled out of a separate file (Additional Health Data); therefore, patients were still eligible for inclusion.

The sensitivity analysis population had a different index date (date of first epilepsy diagnosis during the study time period).

*Index date is defined as:

-date of most recent seizure frequency record (HCRU population);

-date of first seizure frequency record (mortality population);

TQ1 and Q3 refer to the lower and upper quartiles.

‡Townsend score will be missing for patients who do not have a valid postcode entered into the correct field within THIN or who have moved into a recently built housing

development which does not yet have an assigned Townsend score.

$\S$ Patient counts $<6$ or results enabling the calculation of counts $<6$ cannot be disclosed due to restrictions imposed by the UK government to protect patient privacy.

ๆHistory of comorbidities was assessed from the inception of THIN.

$\eta^{* *}$ Including bronchitis and lung disease.

t+Including active symptomatic HIV infection.

$A D H D$, attention deficit hyperactivity disorder; AEDs, anti-epileptic drugs; HCRU, healthcare resource utilisation.

mortality (figure 1). Period prevalence of epilepsy was $0.8 \%$ (95\% CI: $0.80 \%$ to $0.82 \%)$.

The HCRU population was 51\% men with a mean age of 13.2 years, while the mortality population was $53 \%$ men with a mean age of 12.0 years (table 1 ). The Townsend social deprivation quintiles were similar to that of the overall THIN patient population. ${ }^{9}$

The largest proportion of patients (43\% HCRU, 39\% mortality) recorded a seizure frequency of less than once per year at index date. The majority (over 92\%) of patients had a record of epilepsy prior to a seizure frequency record. Over three-quarters of patients $(76 \%$ of HCRU population, $78 \%$ of mortality population) were prescribed AED at index date. Most patients (>69\%) recorded 1-2 AEDs, the most common of which were sodium valproate ( $>32 \%$ of population) and lamotrigine (18\% of both populations).

The most common comorbidity in both populations was asthma (18\% HCRU; 16\% mortality). Learning disability (9\% HCRU; 7\% mortality) and autism (6\% HCRU; 4\% mortality) were also prevalent in the population.

A sensitivity analysis was performed for patients without a record of seizure frequency (index date: epilepsy diagnosis) to explore potential biases towards severe patients. The sensitivity analysis population had a lower prevalence of learning disabilities compared with HCRU and mortality populations. The population was slightly younger at index date compared with the HCRU and mortality populations due to the nature

Table 2 Unadjusted HCRU during the 12-month post-index

\begin{tabular}{|c|c|c|c|c|c|c|}
\hline & \multirow[b]{2}{*}{ All patients } & \multicolumn{5}{|c|}{ Seizure frequency } \\
\hline & & At least daily & At least weekly & At least monthly & $\begin{array}{l}\text { At least once a } \\
\text { year }\end{array}$ & $\begin{array}{l}\text { Less than once } \\
\text { a year }\end{array}$ \\
\hline & $n=1273$ & $n=130$ & $n=146$ & $n=160$ & $n=291$ & $\mathrm{n}=546$ \\
\hline \multicolumn{7}{|c|}{ HCRU during 12-month post-index } \\
\hline \multicolumn{7}{|c|}{ GP visits: overall, any cause } \\
\hline Mean (SD) & $3.39(4.37)$ & $5.25(7.16)$ & $4.56(5.56)$ & $3.88(4.97)$ & $3.31(3.48)$ & $2.54(2.93)$ \\
\hline Median (Q1, Q3) & $2(1,4)$ & $3(1,7)$ & $3(1,5)$ & $2.5(1,5)$ & $2(1,5)$ & $2(1,3.8)$ \\
\hline \multicolumn{7}{|l|}{ Inpatient admissions } \\
\hline Mean (SD) & $0.22(0.77)$ & $0.55(1.54)$ & $0.34(1.01)$ & $0.26(0.63)$ & $0.17(0.56)$ & $0.13(0.46)$ \\
\hline Median (Q1, Q3) & $0(0,0)$ & $0(0,0)$ & $0(0,0)$ & $0(0,0)$ & $0(0,0)$ & $0(0,0)$ \\
\hline \multicolumn{7}{|c|}{ Accident \& emergency admissions } \\
\hline Mean (SD) & $0.31(0.79)$ & $0.51(1.04)$ & $0.4(0.83)$ & $0.38(0.81)$ & $0.32(0.77)$ & $0.21(0.7)$ \\
\hline Median (Q1, Q3) & $0(0,0)$ & $0(0,1)$ & $0(0,0)$ & $0(0,0)$ & $0(0,0)$ & $0(0,0)$ \\
\hline \multicolumn{7}{|c|}{ Hospitalisations: outpatient visits } \\
\hline Mean (SD) & $0.72(1.36)$ & $1.24(2.76)$ & $0.85(1.19)$ & $0.84(1.14)$ & $0.71(1.08)$ & $0.52(1)$ \\
\hline Median (Q1, Q3) & $0(0,1)$ & $0(0,2)$ & $0(0,1)$ & $0(0,1.1)$ & $0(0,1)$ & $0(0,1)$ \\
\hline \multicolumn{7}{|l|}{ AEDs prescribed } \\
\hline Mean (SD) & $1.8(3.1)$ & $3.2(5.06)$ & $2.76(6.32)$ & $1.87(1.77)$ & $1.68(1.62)$ & $1.27(1.56)$ \\
\hline Median (Q1, Q3) & $1(1,2)$ & $2(1,3)$ & $2(1,3)$ & $1(1,2.1)$ & $1(1,2)$ & $1(1,1.1)$ \\
\hline
\end{tabular}

AEDs, anti-epileptic drugs; HCRU, healthcare resource utilisation. 
Table 3 IRR of HCRU encounters

\begin{tabular}{|c|c|c|c|c|c|c|}
\hline & GP encounters & $\begin{array}{l}\text { Inpatient } \\
\text { admissions }\end{array}$ & A\&E admissions & Outpatient visits & AEDs prescribed & Total costs \\
\hline$n(\%)$ of patient with $\geq 1$ use & $1036(81.4)$ & $171(13.4)$ & $255(20.0)$ & 499 (39.2) & $1087(85.4)$ & - \\
\hline Mean (SD) & $3.39(4.37)$ & $0.22(0.77)$ & $0.31(0.79)$ & $0.72(1.36)$ & $1.8(3.1)$ & - \\
\hline $\begin{array}{l}\text { Unadjusted IRR per higher category of } \\
\text { seizure frequency }(95 \% \mathrm{CI})\end{array}$ & $\begin{array}{l}1.20 \\
(1.15 \text { to } 1.26)\end{array}$ & $\begin{array}{l}1.44 \\
\text { (1.27 to } 1.62)\end{array}$ & $\begin{array}{l}1.26 \\
\text { (1.14 to } 1.38)\end{array}$ & $\begin{array}{l}1.23 \\
(1.15 \text { to } 1.31)\end{array}$ & $\begin{array}{l}1.26 \\
\text { (1.22 to } 1.31)\end{array}$ & $\begin{array}{l}1.36 \\
(1.28 \text { to } 1.44)\end{array}$ \\
\hline $\begin{array}{l}\text { Adjusted IRR per higher category of } \\
\text { seizure frequency }(95 \% \mathrm{Cl})\end{array}$ & $\begin{array}{l}1.11 \\
(1.05 \text { to } 1.16)^{*}\end{array}$ & $\begin{array}{l}1.35 \dagger \\
(1.20 \text { to } 1.52)\end{array}$ & $\begin{array}{l}1.20 \ddagger \\
\text { (1.08 to } 1.33)\end{array}$ & $\begin{array}{l}1.15 \S \\
\text { (1.07 to } 1.23)\end{array}$ & -9 & $\begin{array}{l}1.24^{* *} \\
(1.17 \text { to } 1.32)\end{array}$ \\
\hline P value (adjusted) & $<0.0001$ & $<0.0001$ & 0.0008 & $<0.0001$ & $<0.0001$ & $<0.0001$ \\
\hline
\end{tabular}

Personal Social Services Research Unit (PSSRU)/National Health Service tariffs were applied as follows: $€ 37$ for a face-to-face GP visit, £6.45 for general practice visit with someone other than a GP, f14.90 for a telephone encounter, $\mathrm{f} 2708$ for epilepsy-related inpatient admissions, $\mathrm{f} 244$ for outpatient visits (average) and f184 for A\&E admission (average).

${ }^{*}$ Adjusted for age, Townsend score and number of AEDs.

tAdjusted for age.

¥Adjusted for age, Townsend score and number of AEDs.

$\S$ Adjusted for age and Townsend score.

INo factors were found to confound the association between seizure frequency and number of AEDs prescribed.

**Adjusted for age and number of AEDs.

AEDs, anti-epileptic drugs; HCRU, healthcare resource utilisation; IRR: incidence rate ratio.

of index date, with epilepsy likely to be recorded prior to a seizure frequency record (table 1).

\section{HCRU analysis}

HCRU was analysed in the year following index date for 1273 patients. The majority of patients (81\%) recorded $\geq 1 \mathrm{GP}$ encounter. Patients recorded 3.4 GP encounters on average. Outpatient visits were the most frequently recorded use of secondary care (39\% of patients); inpatient admissions were the least common ( $13 \%$ of patients). Patients recorded a mean of 1.8 AED prescriptions over the year of follow-up (table 1).

All HCRU decrease monotonically with decreasing seizure frequency (table 2). Between the highest and lowest seizure frequency categories, inpatient admissions decreased the most with a $76 \%$ decrease $(0.55$ vs 0.13 per year). Decreases were lower for the number of different AEDs prescribed $(60 \% ; 3.2$ vs 1.27 per year), A\&E admissions $(59 \%$; 0.51 vs 0.21 per year) and hospital outpatient visits $(58 \% ; 1.24$ vs 0.52 per year) between the highest and lowest seizure frequency categories. The lowest decrease occurred in the HCRU category with the highest absolute frequency of occurrence; GP visits decreased $52 \%$ (5.25 vs 2.54 per year).

The relationship between seizure frequency and HCRU was determined separately for each component of resource use, where all components increased with seizure frequency in both unadjusted and adjusted analyses (table 3). Adjusted values included the following covariates: age, Townsend score and the number of AEDs. No variables were significant effect modifiers.

\section{Mortality analysis}

In all, 11 patients died during 12490 patient-years of follow-up (mortality rate: 88.1 per 100000 patient-years; 95\% CI: 44 to 158). Higher seizure frequency was related to greater mortality rates (table 4). No deaths were recorded in the lowest category of $<1$ seizure per year, whereas $7 / 354$ patients died in the highest category. There was little difference in mortality rate for patients with seizure frequencies in between these two categories (table 4).

When modelling seizure frequency as a five-level ordinal variable, the unadjusted mortality rate ratio $(95 \% \mathrm{CI})$ suggested an increased rate of 2.56 (1.52 to 4.31) for each category increase in seizure frequency. Only age and number of AEDs at index were confounders: adjustment for increasing age attenuated the mortality rate ratio $(95 \% \mathrm{CI})$ to $2.31(1.37$ to 3.89), whereas number of AEDs attenuated the estimate to 2.28 (1.33 to 3.91 ), and simultaneous adjustment to 2.11 (1.24 to 3.60$)$.

After combining 'at least weekly', 'at least monthly' and 'at least once a year' categories and modelling seizure frequency as a three-level ordinal variable, the unadjusted mortality rate ratio was 9.41 (95\% CI: 3.07 to 28.8 ). Adjustment for age altered this estimate to 7.52 (2.44 to 23.2), adjustment for number of AEDs to 7.28 (2.32 to 22.8 ) and simultaneous adjustment to 6.18 (1.99 to 19.2). Results were similar in sensitivity analyses in which latest recorded seizure frequency was analysed (see online supplementary appendix).

Table 4 Mortality rates for all patients and according to patients' earliest record of seizure frequency

\begin{tabular}{|c|c|c|c|c|}
\hline & $\mathrm{n}, \%$ & Number of deaths & $\begin{array}{l}\text { Patient-time of follow-up } \\
\text { (years) }\end{array}$ & $\begin{array}{l}\text { Mortality rate per } 100000 \text { patient- } \\
\text { years }(95 \% \mathrm{Cl})\end{array}$ \\
\hline Overall & 3324 & 11 & 12490 & 88.1 (44.0 to 157.6$)$ \\
\hline \multicolumn{5}{|l|}{ Seizure frequency } \\
\hline At least daily & $354(10.6)$ & 7 & 1435 & 487.8 (196.1 to 1005.1$)$ \\
\hline At least weekly & $392(11.8)$ & * & * & 63.5 (1.6 to 354.0$)$ \\
\hline At least monthly & $424(12.8)$ & * & * & $59.4(1.5,331.1)$ \\
\hline At least once a year & $862(25.9)$ & * & * & $61.4(7.4$ to 222.0$)$ \\
\hline Less than once a year & $1292(38.9)$ & 0 & 4544 & $0.0(0$ to 81.2$)$ \\
\hline
\end{tabular}

*Patient counts $<6$ or results enabling the calculation of counts $<6$ cannot be disclosed due to restrictions imposed by the UK government to protect patient privacy. 


\section{DISCUSSION}

This UK population-based study using real-world data suggests that CWE with more frequent seizures are associated with greater HCRU, relatively higher healthcare costs and have an increased risk of mortality. Particularly, patients with seizures increasing to at least daily have a substantially increased risk of mortality, inpatient admissions and greater costs.

In the current study, the mortality rate ratio suggested a twofold greater risk of mortality with increasing seizure frequency. The overall mortality rate of 88 (95\% CI: 44 to 158$) / 100000$ personyears was substantially lower than the pooled estimate of 228 (95\% CI: 174 to 282)/100 000 person-years from four CWE incidence cohorts. ${ }^{18}$ One possibility for the observed results is that our study was more recently conducted and lower mortality may reflect improvement in epilepsy management. In support of this, a recent audit of epilepsy deaths in the UK reported low mortality in CWE and delivery of a high-quality service. ${ }^{19}$ Cause of death was not available in THIN, so deaths may or may not have been epilepsy related. In the pooled studies, most excess death in CWE were not seizure related. ${ }^{18}$ Thus, lower mortality may be a reflection of overall decreased all-cause mortality in UK children over time. ${ }^{19}$

Costs and inpatient admissions were shown to increase most substantially with higher seizure frequency. A previous study in the UK indicated that inpatient admissions accounted for the largest proportion of costs in treating epilepsy, ${ }^{20}$ which aligns with our findings that increased seizures can result in greater inpatient admissions and HCRU costs. Costs have been shown to increase substantially in uncontrolled CWE compared with those who have controlled epilepsy, where seizure control by AEDs can lead to a significant reduction in costs. ${ }^{21}$ These findings suggest that effective management with AEDs could improve seizure control and reduce HCRU.

The point prevalence of CWE $(0.8 \%)$ and gender composition is similar to that previously reported in population-based studies in the UK and in Norway. ${ }^{8} 17$ Our results are likely to reflect the general UK CWE population, although we were unable to conduct subgroup analyses for specific epilepsy types in CWE.

\section{Study limitations}

Although THIN is representative of the UK population and quality and outcomes framework, ${ }^{910}$ care outside the GP setting may not have been captured. THIN does not routinely capture data on seizure type nor aetiology so these factors could not be included in analyses. In addition, there is no absolute requirement for GPs to record seizure frequency which is reflected in the high number of CWE which were excluded due to lack of data. Our sensitivity analyses would indicate that CWE included in the study may have more severe epilepsy based on the group having a higher proportion of learning problems ${ }^{17}(9.1 \%$ vs $2.9 \%$ ) compared with the population that had no seizure frequency recorded. Consequently, our results may be slightly overestimated.

The use of earliest seizure frequency rather than latest seizure frequency was explored using a sensitivity analysis to determine whether a time-varying approach would be suitable. The recorded and available seizure frequency values did not change from index in $86 \%$ of CWE; consequently, little additional information would have been added to analyses by including additional records of seizure frequency when few changes were observed.

The proportion of CWE with recorded comorbidities in our study is lower than the up to $80 \%$ reported in other population-based studies that have used both primary and secondary care data, or detailed in-person assessments. ${ }^{1722}$ This may reflect low coding of cognitive and or behavioural comorbidities in THIN since diagnostic codes of conditions are only included if GPs consider them as significant events. ${ }^{8}$ With this restriction, we were unable to stratify CWE into subgroups of complicated versus uncomplicated epilepsy, ${ }^{23}$ but results are likely to reflect CWE in general.

\section{CONCLUSION}

Increased healthcare resource use and mortality risk are associated with increased seizure frequency. Improvement in seizure control may potentially lead to better patient outcomes and reduced healthcare use. At least 50\% reduction of seizures is often the primary efficacy outcome targeted in AED trials, and there are a number of newer AEDs that have successfully attained that target in $30 \%-45 \%$ of the study populations of children with drug-resistant epilepsy, with a smaller proportion of study participants attaining seizure freedom. ${ }^{24} 25$ Thus, although around $30 \%$ of patients with epilepsy do not currently have seizure freedom with existing treatments, even such patients could still have improvement in seizure control. We thus encourage the continued development and use of AEDs with careful, regular consideration of the benefits, adverse side effects and quality of life of patients.

Acknowledgements The authors would like to thank Henrietta Konwea, IQVIA London, for helpful advice on HCRU costing.

Contributors MM and BB designed the study. SP conducted the analysis. MM, WT, DN and RC interpreted the data. MM drafted the manuscript. All authors reviewed and approved the final version of the manuscript.

Funding This work was supported by Eisai Inc.

Competing interests The authors declared the following potential conflicts of interest with respect to the research, authorship and/or publication of this article. RC has received honoraria and study participation fees from Eisai Inc. BB, MM and SP were employees of IQVIA at the time of study conduct. IQVIA received funding from Eisai Inc to conduct the study. WT was an employee of Eisai Inc at the time of study conduct. The lead author affirms that the manuscript is an honest, accurate and transparent account of the study being reported; that no important aspects of the study have been omitted; and that any discrepancies from the study as planned (and, if relevant, registered) have been explained.

Patient consent for publication Not required.

Ethics approval This study received approval from the THIN Scientific Review Committee on 8th August 2016 (reference: 16THIN065).

Provenance and peer review Not commissioned; internally peer reviewed.

Data sharing statement Additional study data may contain patient identifiable information; requests for such data will be reviewed by IQVIA to protect patient confidentiality.

Open access This is an open access article distributed in accordance with the Creative Commons Attribution Non Commercial (CC BY-NC 4.0) license, which permits others to distribute, remix, adapt, build upon this work non-commercially, and license their derivative works on different terms, provided the original work is properly cited, appropriate credit is given, any changes made indicated, and the use is non-commercial. See: http://creativecommons.org/licenses/by-nc/4.0/.

\section{ORCID iD}

Melissa Myland http://orcid.org/0000-0003-2567-3044

\section{REFERENCES}

1 Frost S, Crawford P, Mera S, et al. National statement of good practice for the treatment and care of people who have epilepsy. 2002 http://www.natpact.info/ uploads/textpages.pdf (Accessed 9 Dec 2016).

2 Joint Epilepsy Council of the UK and Ireland. Epilepsy prevalence, incidence and other statistics. 2011 http://www.epilepsyscotland.org.uk/pdf/Joint_Epilepsy_Council_ Prevalence_and_Incidence_September_11_(3).pdf (Accessed 9 Dec 2016).

3 Sander JW. The use of antiepileptic drugs--principles and practice. Epilepsia 2004;45(s6):28-34 


\section{Original article}

4 Neligan A, Sander JW. The prognosis of epilepsy. 2015 https://www.epilepsysociety org.uk/sites/default/files/attachments/Chapter36Neligan2015.pdf (Accessed 15 Jun 2017).

5 NICE. Epilepsies: diagnosis and management | Guidance and guidelines. 2016 https:// www.nice.org.uk/guidance/cg137 (Accessed 9 Dec 2016).

6 Brodtkorb E, Samsonsen C, Sund JK, et al. Treatment non-adherence in pseudorefractory epilepsy. Epilepsy Res 2016;122:1-6.

7 Bautista RE, Glen ET, Wludyka PS, et al. Factors associated with utilization of healthcare resources among epilepsy patients. Epilepsy Res 2008;79:120-9.

8 Meeraus WH, Petersen I, Chin RF, et al. Childhood epilepsy recorded in primary care in the UK. Arch Dis Child 2013;98:195-202.

9 Denburg MR, Haynes K, Shults J, et al. Validation of The Health Improvement Network (THIN) database for epidemiologic studies of chronic kidney disease. Pharmacoepidemiol Drug Saf 2011;20:1138-49.

10 Lewis JD, Schinnar R, Bilker WB, et al. Validation studies of the health improvement network (THIN) database for pharmacoepidemiology research. Pharmacoepidemiol Drug Saf 2007;16:393-401.

11 Greenfield G, Foley K, Majeed A. Rethinking primary care's gatekeeper role. BMJ 2016;354:i4803.

12 Fonferko-Shadrach B, Lacey AS, White CP, et al. Validating epilepsy diagnoses in routinely collected data. Seizure 2017;52:195-8.

13 Gilliam FG, Mendiratta A, Pack AM, et al. Epilepsy and common comorbidities: improving the outpatient epilepsy encounter. Epileptic Disord 2005;7(Suppl 1):S27-S33.

14 PSSRU. Unit Costs of Health and Social Care 2018. 2018 http://www.nhsemployers. org/your-workforce/pay-and-reward/pay/job- (Accessed 18 Dec 2018).
15 NHS. National tariff payment system 2017/18 and 2018/19. 2018 https:// improvement.nhs.uk/resources/national-tariff-1719/.

16 Maldonado G, Greenland S. Simulation study of confounder-selection strategies. Am J Epidemio/ 1993;138:923-36 http://www.ncbi.nlm.nih.gov/pubmed/8256780.

17 Aaberg KM, Bakken IJ, Lossius MI, et al. Comorbidity and Childhood Epilepsy: A Nationwide Registry Study. Pediatrics 2016;138:e20160921.

18 Berg AT, Zelko FA, Levy SR, et al. Age at onset of epilepsy, pharmacoresistance, and cognitive outcomes: A prospective cohort study. Neurology 2012;79:1384-91.

19 Royal College of Paediatrics and Child Health. Coordinating Epilepsy Care: A UK-Wide Review of Healthcare in Cases of Mortality and Prolonged Seizures in Children and Young People with Epilepsies.. 2013 http://www.rcpch.ac.uk/system/files/protected/ page/CHRUK_Module B low res_0.pdf (Accessed 13 Jun 2017).

20 Jacoby A, Buck D, Baker $G$, et al. Uptake and costs of care for epilepsy: findings from a U.K. regional study. Epilepsia 1998;39:776-86.

21 Beghi $\mathrm{E}$, Frigeni $\mathrm{B}$, Beghi $\mathrm{M}$, et al. A review of the costs of managing childhood epilepsy. Pharmacoeconomics 2005;23:27-45.

22 Reilly C, Atkinson P, Das KB, et al. Neurobehavioral comorbidities in children with active epilepsy: a population-based study. Pediatrics 2014;133:e1586-e1593.

23 Berg AT, Rychlik K, Levy SR, et al. Complete remission of childhood-onset epilepsy: stability and prediction over two decades. Brain 2014;137:3213-22.

24 Trinka E, Steinhoff BJ, Nikanorova M, et al. Perampanel for focal epilepsy: insights from early clinical experience. Acta Neurol Scand 2016;133:160-72.

25 Devinsky O, Cross JH, Laux L, et al. Trial of Cannabidiol for Drug-Resistant Seizures in the Dravet Syndrome. N Engl J Med 2017;376:2011-20.

26 Sillanpaa M, Schmidt D. Early seizure frequency and aetiology predict long-term medical outcome in childhood-onset epilepsy. Brain;132:989-98. 